\title{
A orilla del acantilado
}

\section{Aída Martínez-Zúníiga}

Al este del farallón, a orilla del acantilado.

Observo el mar plomizo bufando a mis pies, diez metros abajo. Ahí se congeló mi vida, cuando la imagen impactó mis neuronas y se grabó en mi memoria como un sello lacrado al rojo vivo.

Había imaginado múltiples escenas para semejante frase inicial de un texto. Mi favorita era la romántica, en la cual llegaba al acantilado, ribeteado en oro, frente al mar turquesa de suaves olas que rompían bajo mis sandalias de perlas. Ahí flotaba sutil hasta un improvisado altar de flores, donde me comprometía con el amor de mi vida.

La cálida brisa me estrechaba y no podía sentirme más feliz en aquella sublime postal, replicada en mis sueños desde tiempos remotos. Me rodeaban familiares y amigos, que compartían conmigo la alegría de existir y disfrutar de las cosas simples, como una boda en comunión con la naturaleza. ¿Qué más podría pedir? 
Sin embargo, el cuento no resultó así. Al parecer, no me iban ni los inicios ni los finales románticos.

En cambio, estoy aquí, en mi acantilado de plomo, donde las olas gruñen al estrellarse contra las rocas afiladas y la brisa me araña la cara. El gorro, la bufanda y el abrigo no logran cobijar mi estremecido cuerpo, minado por el cáncer.

La vida suele parecer bella cuando crees que todo lo tienes y todo lo puedes. Trabajas, acumulas y deshechas: ropas, autos, amistades, parejas, compromisos y todo aquello que te estorba.

Corres frenética, de un lado a otro, para hacer rendir el tiempo y conseguir tus metas. Viajas y das vueltas por el mundo, revisas mapas en busca de un acantilado de oropel, como deseando llegar a Camelot.

Hasta que un día, en medio de tu maniaca búsqueda, llega la fatal sentencia: tienes cáncer. Y todo se paraliza, el sol se apaga, la luna no brilla, las aves no cantan, tampoco susurran los árboles, y tú no respiras.

No existe un amor de tu vida que te consuele, ni hijos que te retengan, ni una madre en quien puedas refugiarte o un padre que te sostenga. La soledad del moribundo es inmensa, no caben en ella palabras alentadoras, ni terapias alternativas, ni ayudas espirituales.

Y te enojas y te revelas y reclamas a Dios; ese Dios sordo e indiferente en el que hace mucho dejaste de creer. ¿Cuándo?

Cuando te quedaste plantada a unos pasos del altar, o cuando saliste como una autómata de una clínica de mala muerte, con el vientre vacío y el alma en el infierno, irecuerdas?

No hay divinidad ni ser en el mundo que puedan confortarte, porque ahora envidias cualquier signo de vida a tu alrededor. Y duelen los amaneceres y el sol, la lluvia o el frío, los planes que ya no realizarás, las palabras que no dirás, porque sabes que pronto ya no tendrás nada de eso.

Porque te irás y la vida continuará sin ti, no se alterará el rumbo de la historia, serás una anécdota en el recuerdo de quienes te conocieron. Y poco a poco se borrará tu sombra y tu nombre quedará plasmado solo en una vieja lápida.

Y entonces: «Al este del farallón, a orilla del acantilado».

— ¿Ya tienen la frase, puedo borrarla? — la voz del profesor te devuelve a la realidad. - Quiero que me traigan un cuento basado en esta frase para la próxima semana. ¿Alguna duda?

-Ninguna. Quedó todo claro. 


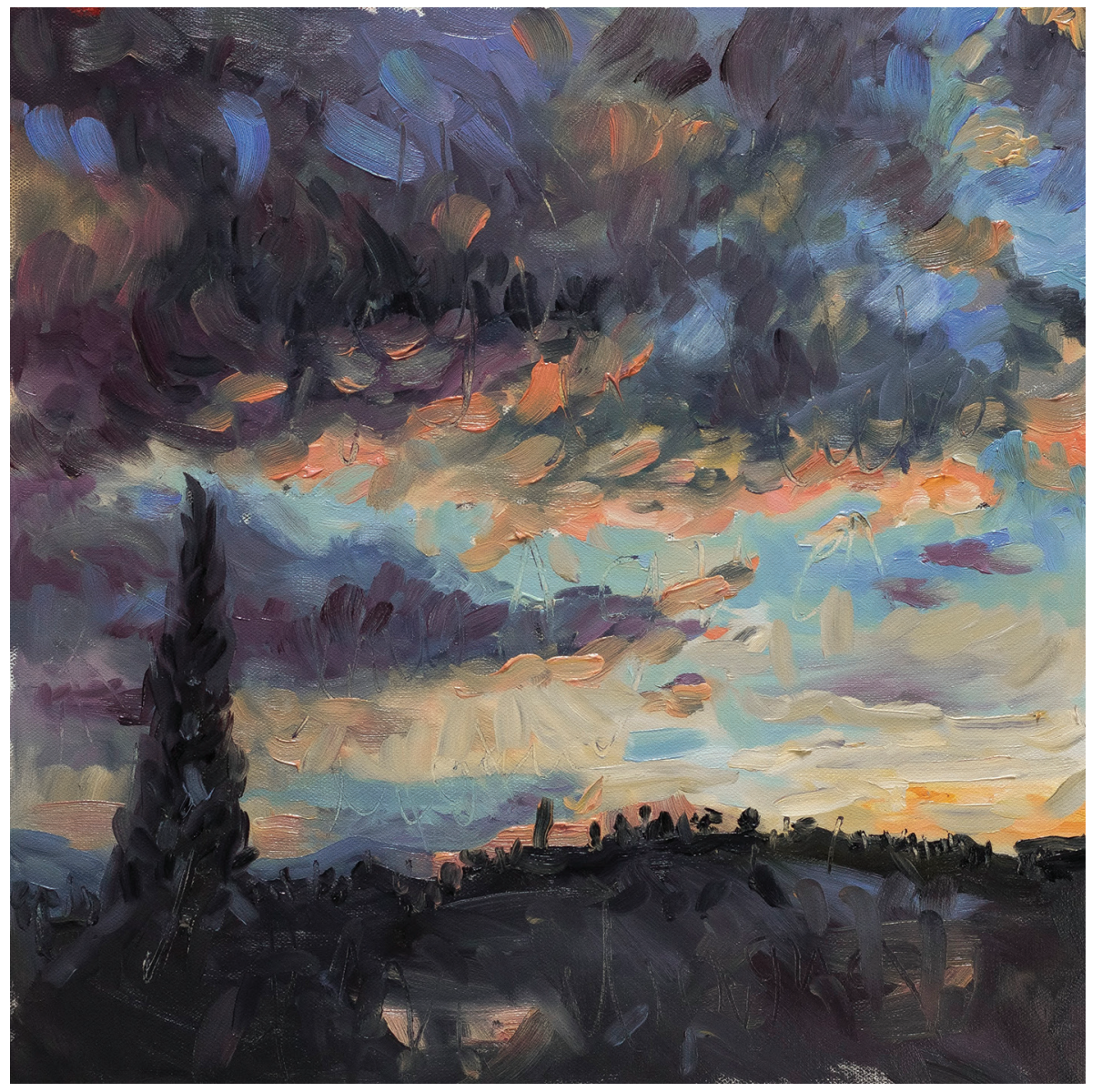

El agua y sus presagios, de la serie Mar incendiado (2021). Óleo sobre lino: Xilberto Loera-Núñez. Prohibida su reproducción en obras derivadas.

AidA M. ZúNiga. Nació en la Ciudad de México. Estudió la Licenciatura en Ciencias de la Comunicación en la Facultad de Ciencias Políticas y Sociales (FCPyS) de la Universidad Nacional Autónoma de México (UNAM), México. Se ha desempeñado profesionalmente en el área de difusión de instituciones educativas, como redactora y correctora de estilo. Cursó talleres de redacción periodística, creación literaria y edición de revistas en diferentes recintos universitarios. Publicó su primer cuento corto llamado "Como un sueño" en la Gaceta de la FCPyS de la UNAM. Ganadora en el Tercer Certamen Nacional de Cuento organizado por Escritoras MX en 2020, con el relato "Una mujer vestida de luna roja". Ha publicado cuentos en espacios digitales, como Escritoras Mexicanas, El Búho y Crónica de Oaxaca.

Recibido: 15 de mayo de 2020

Aprobado: 7 de enero de 2021 